كلمة التحرير

\title{
إسماعيل راجي الفاروقي وواجب الوفاء
}

\section{هيئة التحرير}

شهد العالم الإسلامي ظهور العديد من المفكرين والمصلحين والمدارس الإصلاحية، أمثال الأفغاني ومحمد عبده والكواكبي ومحمد رشيد رضا وابن عاشور، إلخ، الذين حاولوا

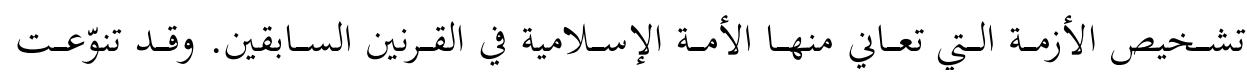

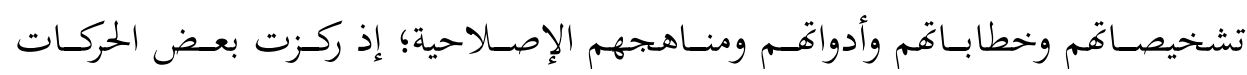

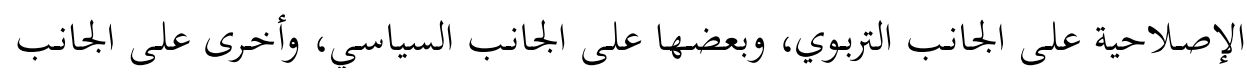

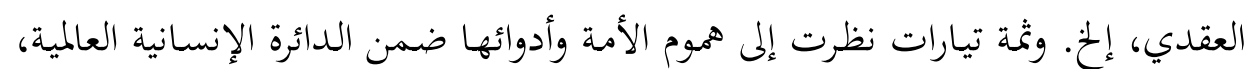

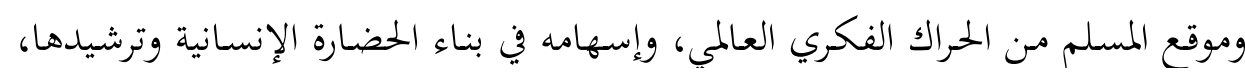

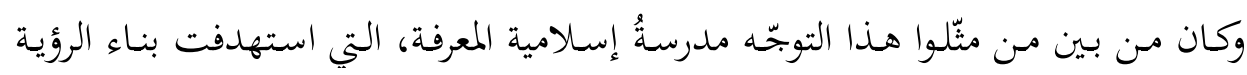

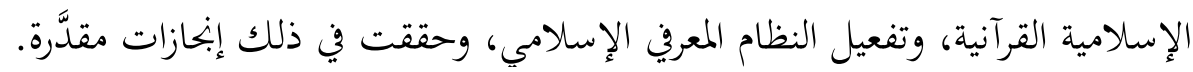
ويُعـد إسماعيل الفـاروقي مـن أبرز شخصيات الإصـلاح الفكري الإسـلامي وجهـود

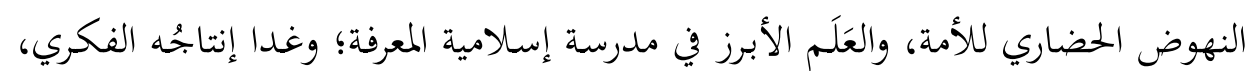

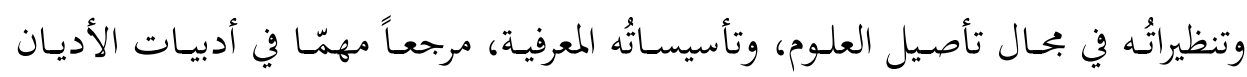

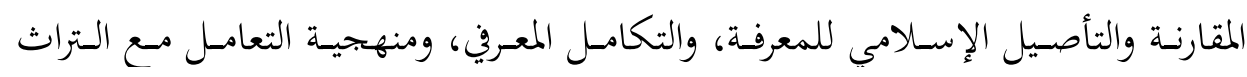

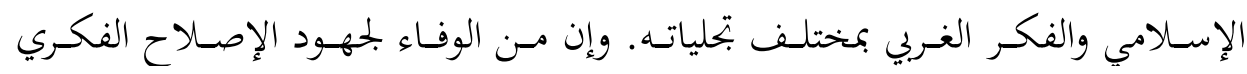

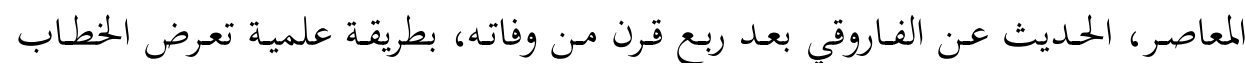
الإصلاحي الفكري الذي أسهم في تأسيسِه وتحليلِه وتنقدُه.

لا نعرف أحداً تعرّف على الدكتور إسماعيل راجي الفـاروقي، يرحمه الله، إلا ويذكر

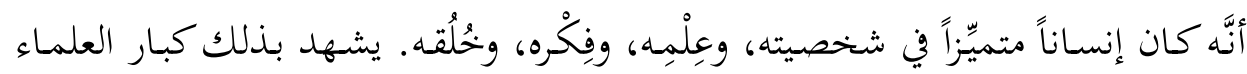

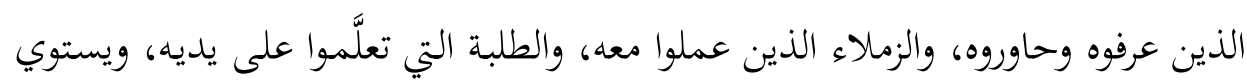

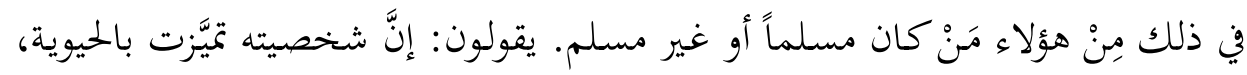




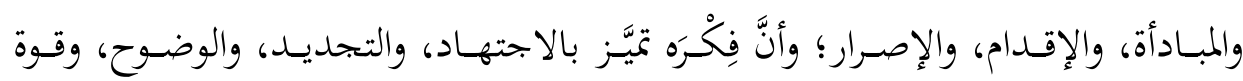

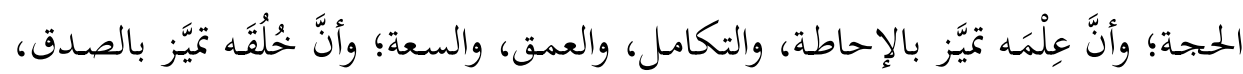

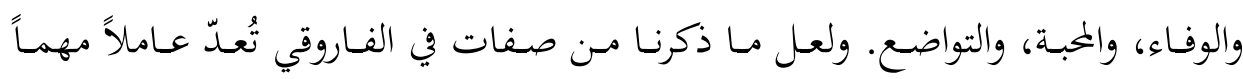

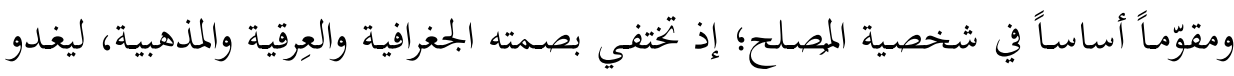

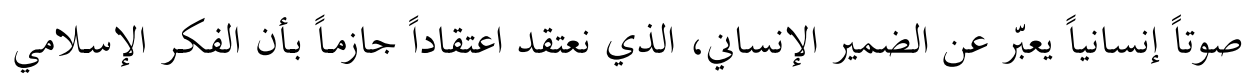
أصدق من يُعبّر عن هذا الضمير.

تـألَّق إسماعيـل الفـاروقي في عـدد مـن البحـالات، فتـــ جمـع مـن العلـوم الاجتماعيـة

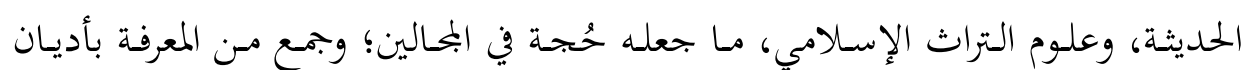
العالم القديمة والحديثة مـا جعل كتاباته فيها مـادة مرجعية للباحثين والمتخصصصين. وقـد وعى الفـاروقي أهمية التكامل المعرفي بين العلوم الاجتماعية والإنسانية مـ جهة، وعلوم

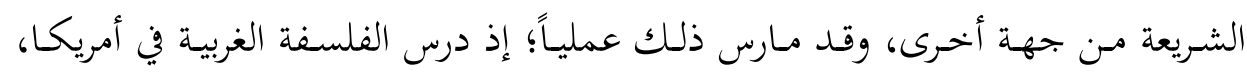

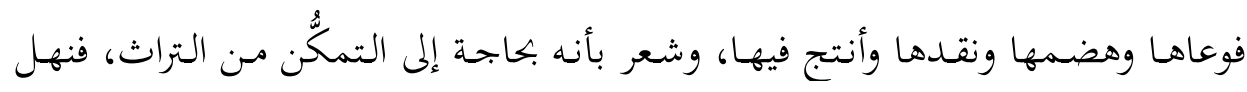
الدراسات الشرعية من الأزهر، وكان لهذا الوعي في فهم الذات والآخر، والمزج بين العلوم

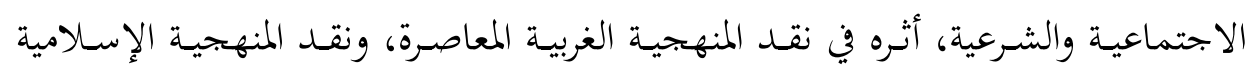
التقليدية، وإبراز الحاجة إلى إحداث التركيبة الخلاّقة على حدّ قوله. ومع أنَّه فيلسوف بحكم التخصص والممارسة، ومفكِّر بحكم العطاء والإبجاز، فقـد

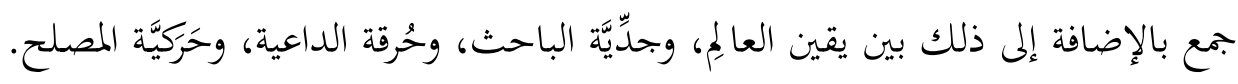

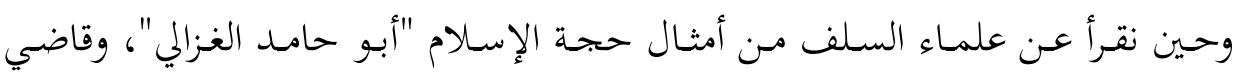

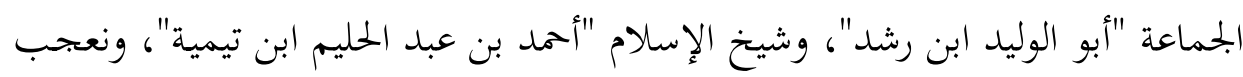

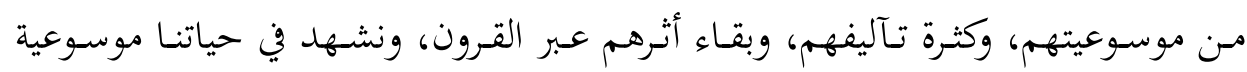

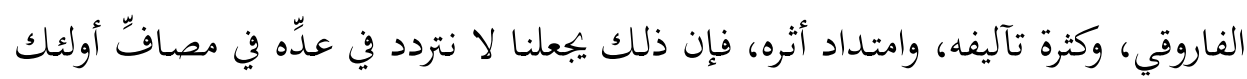

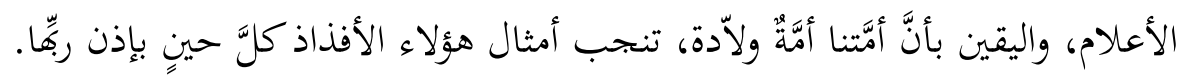

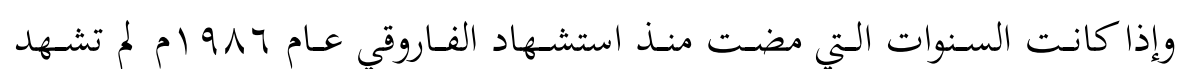
جهوداً كافية للتعريف به وبإبحازاته وبإسهاماته، فإننا نأمل أن يقيّض الله لهذه الإنجازات 


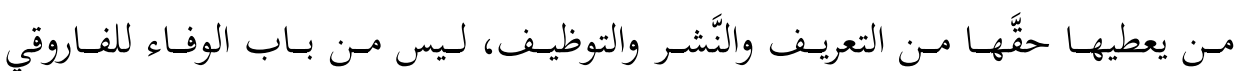
والاعتراف بفضله وحسب، وإنما لأنّ أجيال الأمة بحاجة ماسّة إلى العلم بهذه الإبحازات، وتوظيفها، والبناء عليها. ولعلّ من حسن الطالع أن نلحظ أن الاهتمام المنشود بالفاروقي

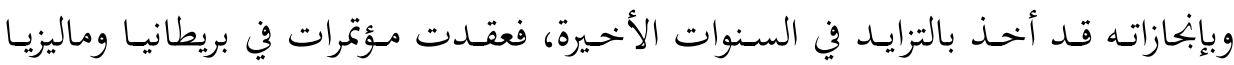

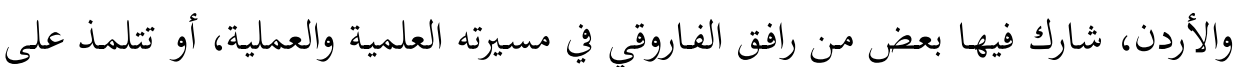
يديه في الدراسـة. كمـا شـارك فيها عـدد مـن الباحثين والعلمـاء الذين دفعهم تأثرهم بمـا قرأوه مـن مؤلفـات الفـاروقي، إلى الكشـف عـن جوانـب مـن الأهميـة والتميّز في أفكـاره والحاجـة إلى نشـرها وتوظيفها، لا سـيما أن الفـاروقي قـد استقر في بحتمـع يهكمـه نظـام معري غربي يختلف كلياً عن النظام المعري الإسلامي، من حيث المصدر والرؤية والأداة والغايـة والبنينة، فحـاول نقـد الأسـس الفلسفية والعقديـة للنظـام المعرفي الغربي، عـاملاًا في

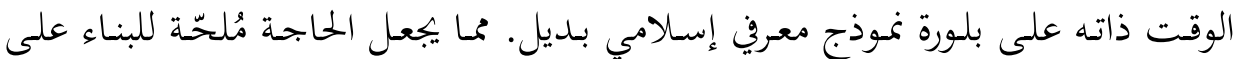
إرث الفاروقي، والانطلاق مما انتهى إليه لا مما بدأ به.

ومن المعروف أن الفـاروقي كان يهاضر ويكتب بالعربية والإبحليزية والفرنسية، لكن.

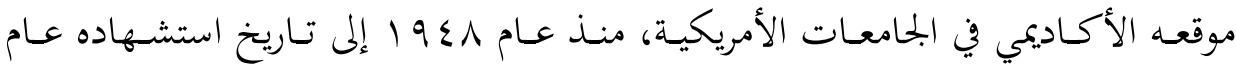

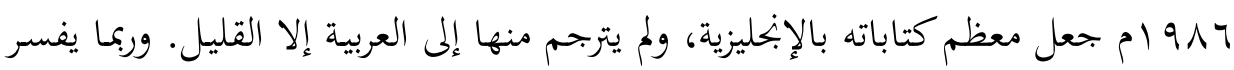
ذلك الضـفف الملحـوظ في حضـور الفـاروقي في السـاحة الفكريـة والثقافيـة والأكاديميـة العربية، بالمقارنة بحضوره في البلدان الإسلامية غير العربية. فضلاً عن أسباب أخرى تعود إلى الحصار الذي تعرّض له الفاروقي، نتيجة المعارك المبدئية والمواقف الصلبة التي الخذها

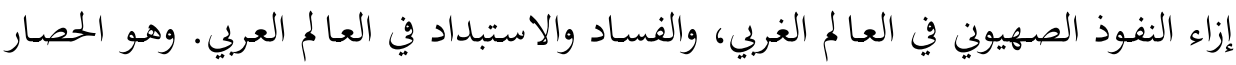
الذي انتهى بتصفيته الجسدية، فقتل شهيداً مع زوجته ورفيقة علمه وجهاده، في منزله في

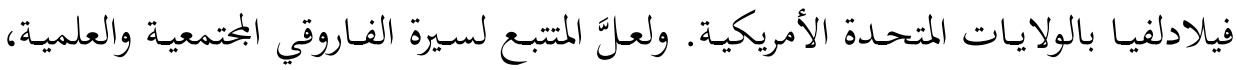
سيكتشف الجهاد الفكري الذي كان يُنظّر له الفاروقي ويمارسه، في جميع الدوائر المعرفية والمؤسسات الفكرية والثقافية والأكاديمية والبحثية، سواء أكانت من الدائرة المعرفية الغربية

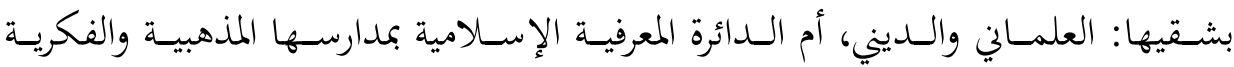
والفلسفية. لذلك رأيناه طاقة لا يكلّ ولا يملّ، وكأنّه يسابق الزمن حتى يحقق أكبر قدر 


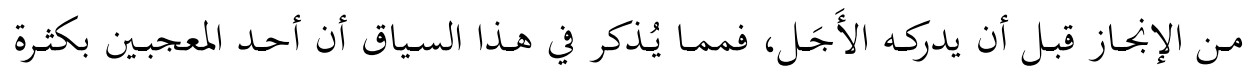

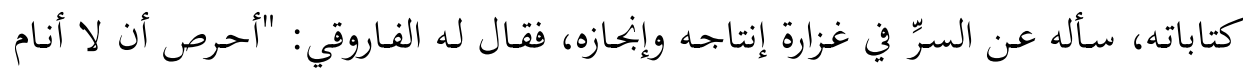

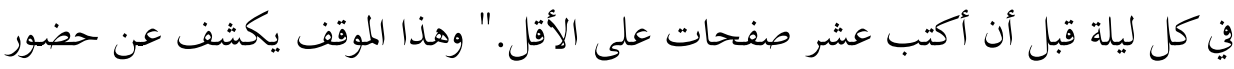

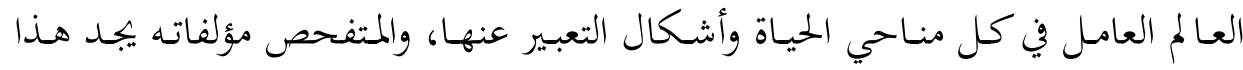

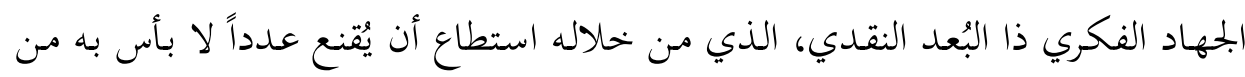

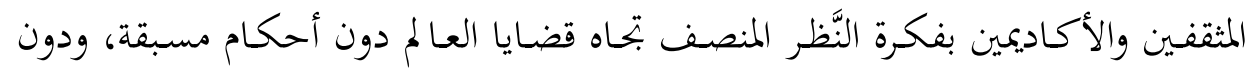

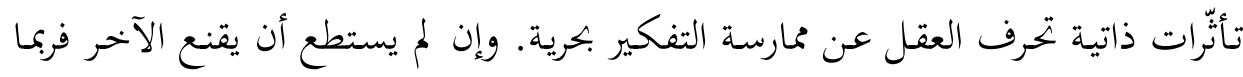

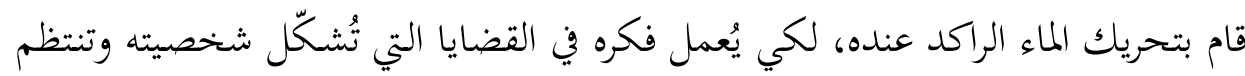
drait

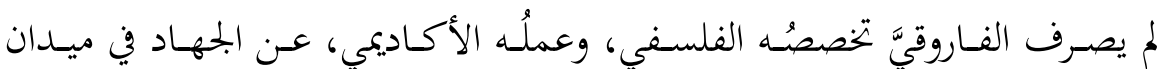

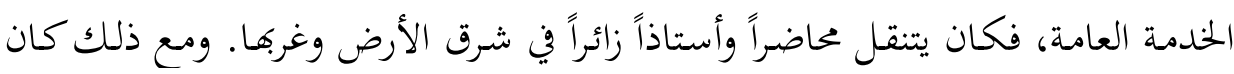

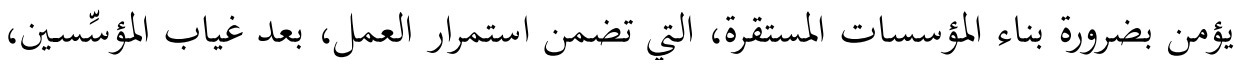

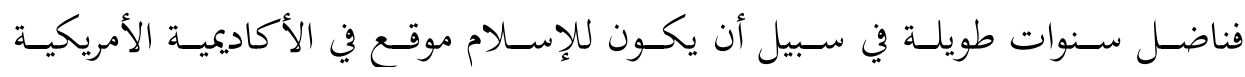

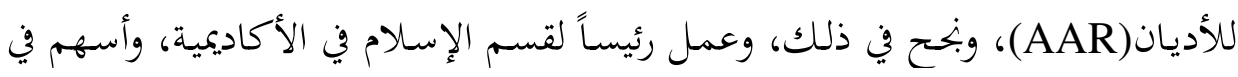

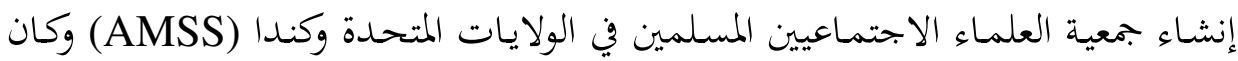

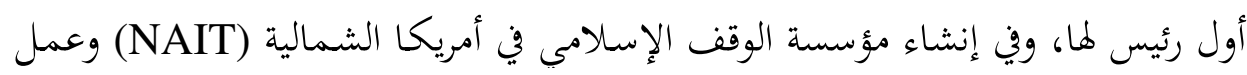

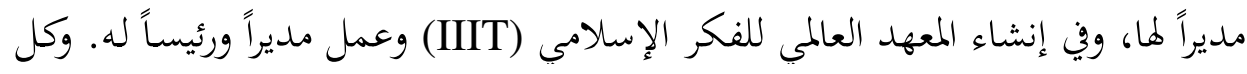
هذه المؤسسات استمرت ولا تزال في عملها.

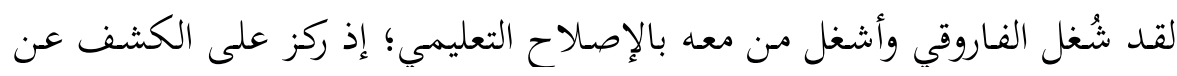

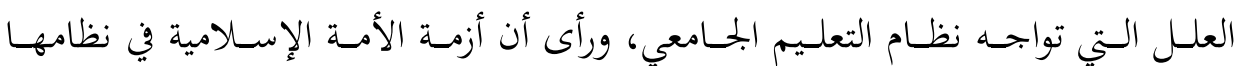

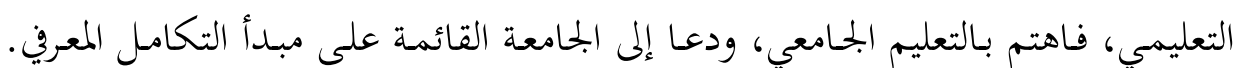

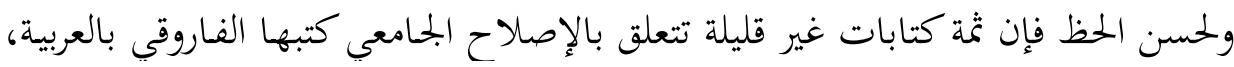

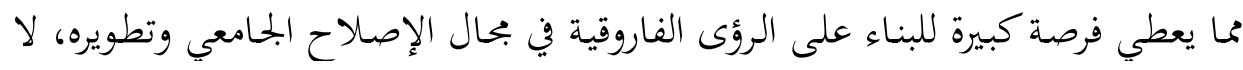

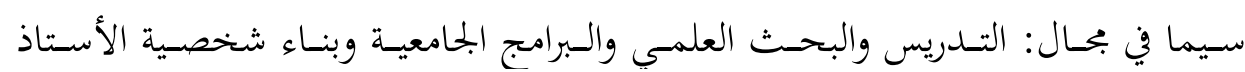
الجحامعي المتسقة مع هوية الأمة. 
ولعل المؤتمر العلمي الذي نظّمه المعهد العالمي للفكر الإسلامي في الأردن، بالتعاون

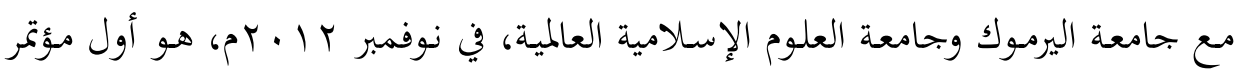

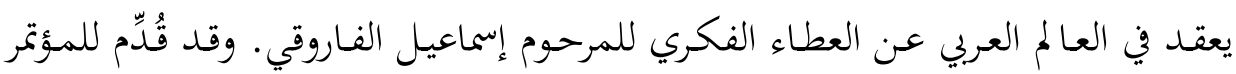

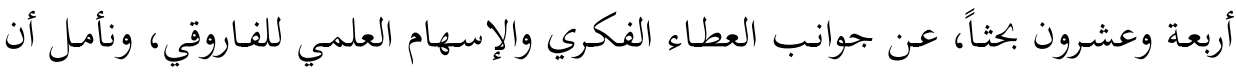

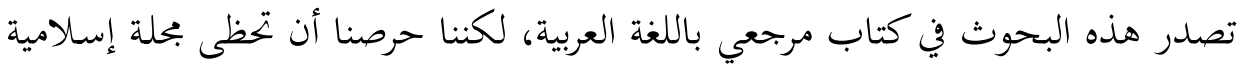

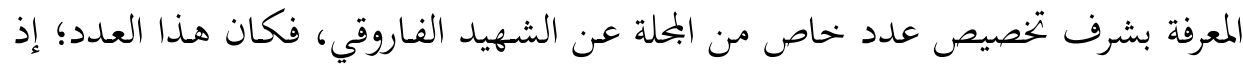

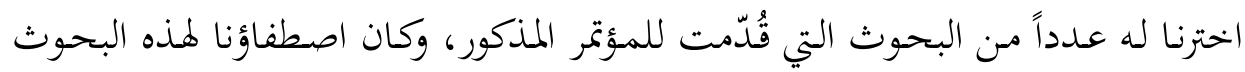

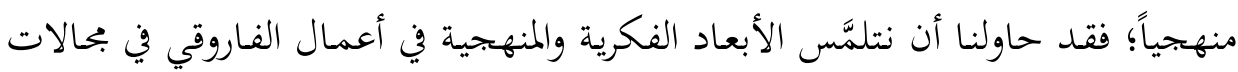
معرفية وقضايا فكرية متنوعة، لنرسم خارطة فكرية للفاروقي ما استطعنا إلى ذلك سبيلا.

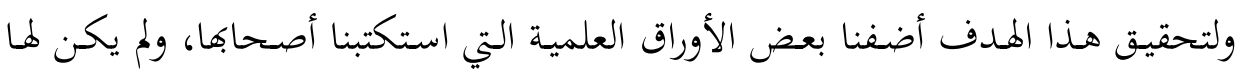

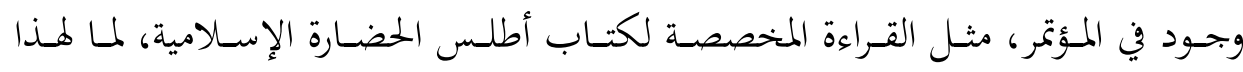
الكتاب من أهمية في الكشف عن منهج الفاروقي في معالجة الأبعاد الحضارية والثقافية -

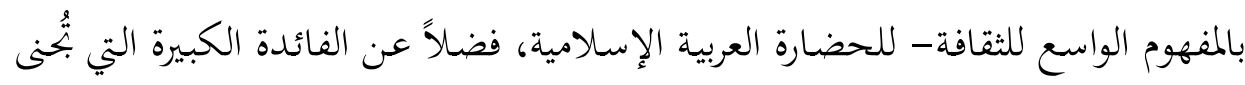

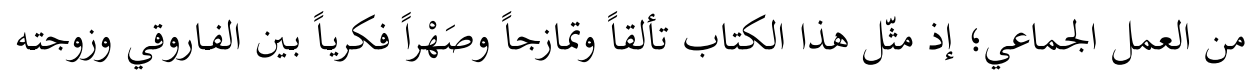

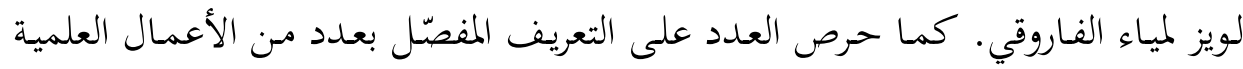

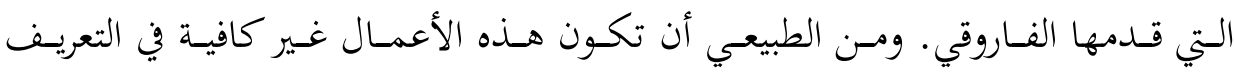

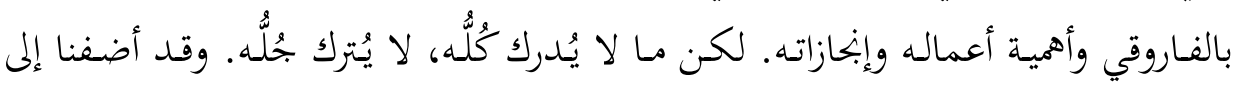

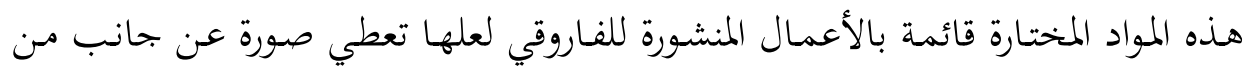

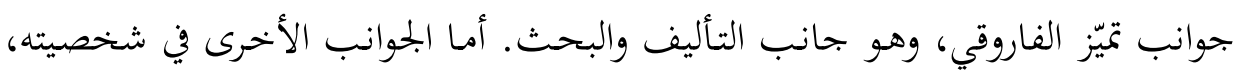

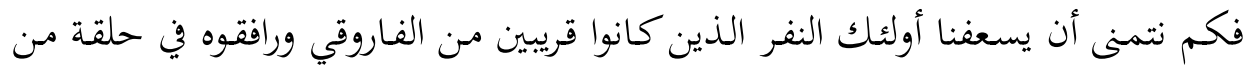

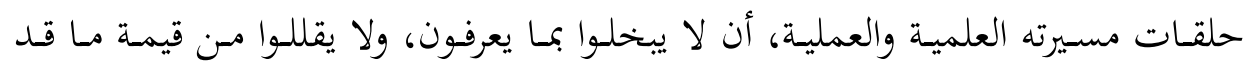

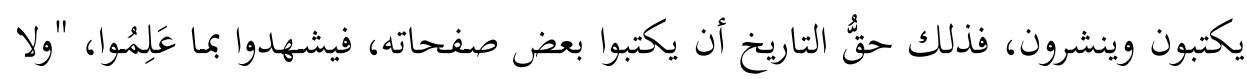

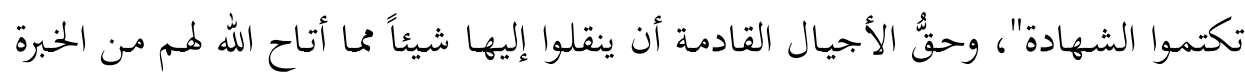




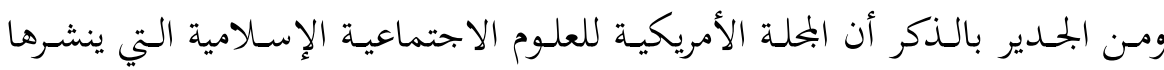

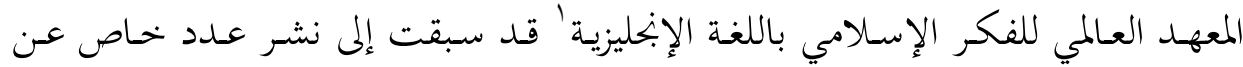

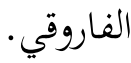

ومـن المؤسف حقـاً أن نلاحظ أن العقل المسلم المعاصر مـا زال يعيش مرحلة التيه

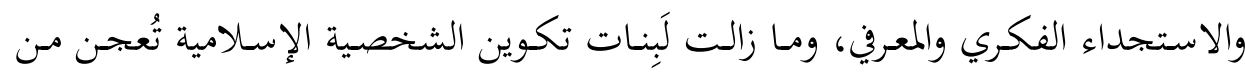

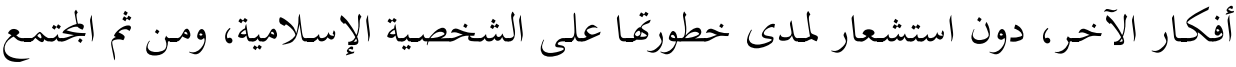

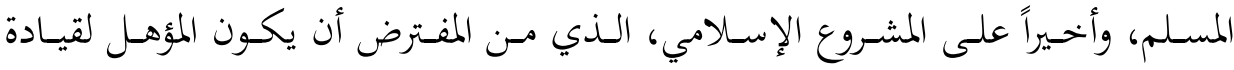

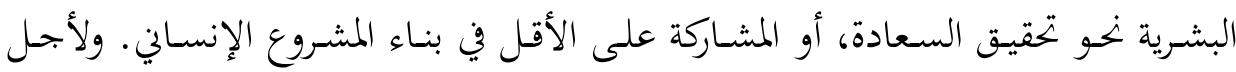

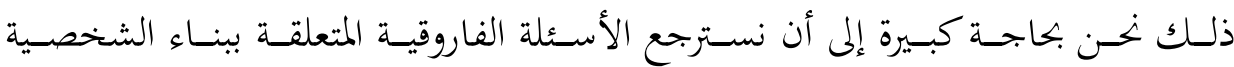

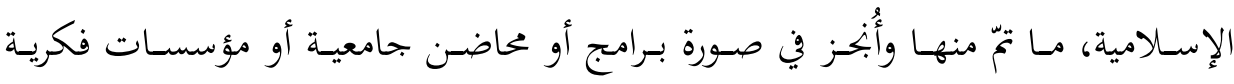

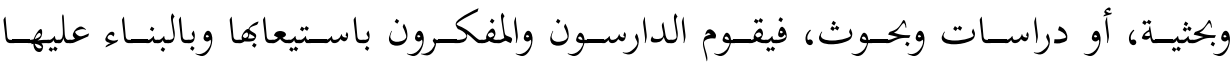

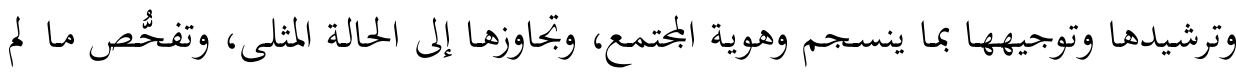

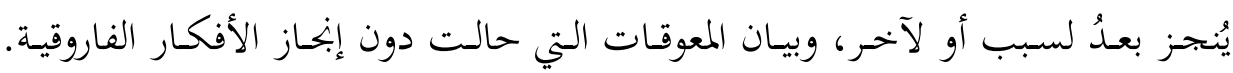

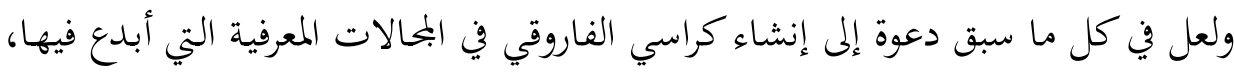

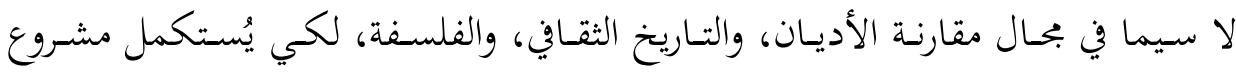
الفاروقي الهادف إلى هضة هذه الأمة.

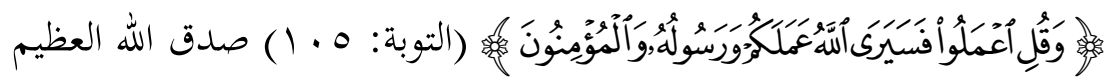

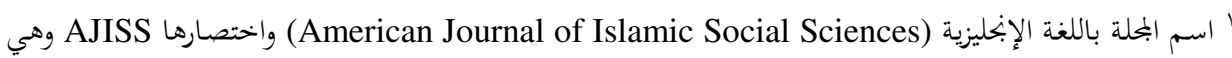

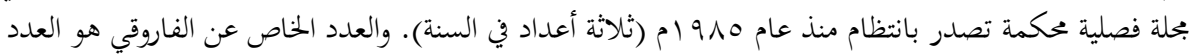

